\title{
Determination of Phenolic and Antioxidant Properties in Tea and Spent Tea Under Various Extraction Method and Determination of Catechins, Caffeine and Gallic Acid by HPLC
}

\author{
N. I. Nadiah ${ }^{\#}$, U. Uthumporn ${ }^{\# 1}$ \\ \# School of Industrial Technology, Universiti Sains Malaysia, Minden, Penang, 11800, Malaysia \\ E-mail: sapina@usm.my
}

\begin{abstract}
Tea (Camellia sinensis L.) contain high phenolic compounds and antioxidant elements, while spent teas originating as the main byproduct of beverage tea manufacturestill contain some level of antioxidant elements. The purpose of the present study is to compare the effect of different extraction condition and to determine the chemical compound present in black tea (BT), oolong tea (OT), green tea (GT), spent black tea (SBT), spent oolong tea (SOT) and spent green tea (SGT). Theextraction experiment were carried out by the conventional solid-liquid method, using boiling water $\left(100^{\circ} \mathrm{C}\right)$ and $50 \%$ ethanol concentration, with extraction period of 5 minutes. The influence of these extraction methods on the content of total phenolic compounds and antioxidant activities of the extracts were evaluated. Flavanoid, gallic acid, caffeine and four catechins (catechin (C), gallocatechin (GCG), epicatechin (EC) and epigallocatechin (EGC)) were found in all of the extracts and were quantified by utilizing High Performance Liquid Chromatography (HPLC) analysis tool. GT extraction using 50\% ethanol concentration was found to be the most suitable method to produce an extract with high content of phenolic compounds ( $186.83 \mathrm{mg}$ GAE/100 g tea) and high antioxidant activities (FRAP of $3814.29 \mu \mathrm{mol} \mathrm{Fe}(\mathrm{II}) / \mathrm{g}$ ), simultaneously. The results shown that GT had higher total flavanoids value at $347.67 \mathrm{mg}$ CEQ/g followed by OT $(295.00 \mathrm{mg} \mathrm{CEQ} / \mathrm{g})$ and than the BT $(187.33 \mathrm{mg} \mathrm{CEQ} / \mathrm{g})$. The analytical HPLC results obtained also indicated that GT contained higher amount of catechins than OT, BT, SGT, SOT and SBT due to fermentation process during the tea manufacturing, which reduces the levels of catechin significantly. All four catechins were detected in GT. However, epicatechin, and gallocatecin gallate are the major catechin present in SGT.
\end{abstract}

Keywords - Spent tea, normal tea, phenolic content, flavanoid content, FRAP assay, DPPH inhibition, HPLC

\section{INTRODUCTION}

Globally, Tea (Camellia sinensis) is second in line after water under popular beverages due to its phenomenal taste and outstanding benefits towards health [1]. Approximately 5000 years ago, tea was first consumed in China for its medicinal properties, while in current era tea had been widely recognized for health benefits pertaining to increased public awareness of the high flavonoid content of the tea leaves and extracts [2],[3]. Tea polyphenols behaves as natural antioxidant [4] and some studies suggest that regular consumption of tea can reduce the risk of developing a variety of cancers, namely colon, pancreatic, and stomach cancers [5]-[7].

Tea leaves contain 10-30\% of dry weight of polyphenols, including catechins, flavonols, flavanones, phenolic acids, glycosides and the aglycones of plant pigments [8]. Tea extracts are powerful antioxidants and the major tea catechin are (-)-epicatechin, (-)-epigallo- catechin, (-)- epigallocatechin gallate and (-)-epicatechin gallate [9]. The main tea phenolic acid is gallic acids, while it also contains certain amount of caffeine. Among the composition of tea, some well known elements are catechins, phenolic acid and caffeine. However, in commercial tea beverages, the composition differs with species, season, horticultural conditions and particularly with the degree of fermentation during the manufacturing process.

There are three types of tea: green, oolong, and black, which are produced from a single plant species, and the varieties are distinguished via the processing technique. During the processing phase, Green tea will not be fermented, Oolong tea will be partially fermented and black tea will be completely fermented [10]. In general, the polymerized polyphenols level is determined by the magnitude of the fermentation. Green, oolong and black tea are produced from young shoots, primarily the initial 2-4 leaves and the bud. After various processing stages, such as withering, rolling, fermentation, drying, and finally packing; 
green tea leaves are converted into black tea leaves. Investigations have indicated that black teas contains smaller amounts of polyphenols that also exhibit antioxidant behaviour [11],[12].

Normally, consumers all over the world enjoy tea by brewing tea leaves in hot-boiled water for 2 to $3 \mathrm{~min}$, and usually the time for brewing tea is not sufficient to extract the complete phenolic content from the tea leaves. Spent tea leaves or tea wastes are the tea leaves left after the preparation of the beverage. Spent tea leaves could be a source of natural polyphenols, because it might contain residual phenolic compounds that have not been completely extracted from the tea leaves during the brewing process. Nevertheless, spent tea leaves have received little attention on their bioactive compound and bioactivities. In this paper, an investigation [3] on the usage of spent tea had been proposed, which can be used as a potent natural antioxidative sources. This is beneficial to our environment and saves the cost of energy as we can transform the agricultural waste into a functional product.

Earlier work on phenolic compound extraction from fresh spent tea samples were conducted with the aid of solvents, including methanol, ethanol, acetone, propanol, ethyl acetate and dimethylformamide with different water concentration [13]. The recovery of polyphenols from plant materials is affected by the solvent system in terms of its solubility of phenolic compounds used for the extraction process. Solvent polarity is another factor that should be considered carefully since it plays an important role in increasing the solubility of phenolic compound within the solvent [14]. As part of the investigation, ethanol was used as the solvent for the extraction of polyphenols from the tea leaves. Ethanol is chosen due to enabling higher recovery of polyphenols from selected tropical fruits compared to methanol [15].

Various extraction methods affect the extraction yield and antioxidant activity of tea extracts. Some studies on the extraction conditions of active antioxidant components from green tea leaves have been reported [1],[7],[15],[16]. However comparable studies on the effect of various extraction methods on the antioxidant activity of oolong tea, black tea and their spent tea extracts were not carried out. The purpose of this work is to compare the effects of two conventional solid-liquid extraction methods, namely with hot water $\left(100^{\circ} \mathrm{C}\right)$ and $50 \%$ of ethanol concentration of phenolic, and antioxidant activity of GT, OT, BT, SGT, SOT and SBT extracts. Additionally, the study will also determine the gallic acid, caffeine and four catechins content in the extract by using HPLC method.

\section{MATERIAL AND METHODS}

\section{A. Type of Chemicals}

The chemicals used within this investigation are as follows: Folin-Ciocaltue reagent, gallic acid, sodium nitrite solution, aluminium chloride, sodium hydroxide $(\mathrm{NaOH})$, 2,2-diphenyl-1-picrylhydrazyl (DPPH) reagent, 2,4,6-tris(2pyridyl)-5-triazine (TPTZ) solution, $\mathrm{FeCl}_{3} \cdot 6 \mathrm{H}_{2} \mathrm{O}(20 \mathrm{mM})$ solution, concentrated hydrochloric acid $(\mathrm{HCl})$; where all of the chemicals were purchased from Sigma Chemical (Selangor Malaysia).

\section{B. Sample preparation}

The tea leave samples were purchased from a supermarket in the Penang. The spent tea was prepared by weighing $100 \mathrm{~g}$ of tea leaves from BT, OT and GT, subsequently brewed in $1000 \mathrm{ml}$ of hot water $\left(100^{\circ} \mathrm{C}\right)$ for 5 minutes, and followed by filtering and drying processes in air dried oven for 48 hours.

In order to perform extraction, the samples (1g) were infused in $100 \mathrm{ml}$ of (a) distilled water at $100^{\circ} \mathrm{C}$ and (b) aqueous ethanol at $50 \%(\mathrm{v} / \mathrm{v})$. After the 5 minutes extraction process, the infusions were filtered through a tea strainer. The filtrates collected from the extraction process are placed in reagent bottles and covered with aluminium foil to avoid light exposure. The extracts were stored at the temperature of $4^{\circ} \mathrm{C}$ for further analysis. Each of the extraction were done in a triplicate terms $(n=3)$.

\section{Determination of total phenols}

Total phenol content (TPC) was determined according to the Folin-Ciocaltue assay method as reported in [16]. Briefly, $300 \mu \mathrm{L}$ of the sample, in triplicate terms, were introduced into the test tubes, followed by $1.5 \mathrm{ml}$ of Folin-Ciocaltue reagent (diluted up to tenfold with distilled water) and $1.2 \mathrm{ml}$ of sodium carbonate $(7.5 \%, \mathrm{w} / \mathrm{v})$. The tubes were mixed and placed in a dark room for 30 minutes at room temperature $\left(25 \pm 1{ }^{\circ} \mathrm{C}\right)$. The absorbance was measured at $765 \mathrm{~nm}$ using UV-visible spectrophotometer (Shimadzu UV-160A PC, Shimadzu Corporation, Kyoto, Japan), and subsequently Gallic acid was used for constructing the standard curve. The TPC was expressed as mg gallic acid equivalent (GAE), per $100 \mathrm{~g}$ wet weight material. Gallic acid standard were prepared by diluting $100 \mathrm{mg}$ of pure Gallic acid in one liter of distilled water. A series of standard Gallic acid were prepared at 20, 40, 60, 80 and $100 \mathrm{mg}$ of pure Gallic acid concentration as the reference curve.

\section{Determination of flavonoids}

Total flavonoid content (TFC) was determined according to the method proposed in [17] by using the aluminium trichloride. Briefly, $500 \mu \mathrm{l}$ of the extract solution was added to a test tube with $2.5 \mathrm{ml}$ of distilled water, subsequently, about $150 \mu \mathrm{l}$ of sodium nitrite solution $(5 \% \mathrm{w} / \mathrm{v})$ was added to the mixture and kept for 5 minutes, followed by adding $300 \mu \mathrm{l}$ of aluminium chloride. At the 6th minute, $1 \mathrm{ml}$ of 1 $\mathrm{M}$ sodium hydroxide $(\mathrm{NaOH})$ was added to the solution. The mixture was further diluted with $550 \mu$ of distilled water, and shaken vigorously. The absorbance of the mixture was measured at $510 \mathrm{~nm}$ using UV-visible spectrophotometer (Shimadzu UV-160A PC, Shimadzu Corporation, Kyoto, Japan) and the TPC was expressed as mg quercetin (QE) per 100 g sample.

\section{E. Determination of ferric reducing/antioxidant power (FRAP assay)}

The power reduction of the extracted samples were determined according to the method reported in [18], whereby the color measurement of ferrous-tripyridyltriazine complex, formed via ferric to ferros ion reduction at low $\mathrm{pH}$, will be carried out. . FRAP reagent was freshly prepared by mixing $100 \mathrm{ml}$ of acetate buffer $(0.3 \mathrm{M}, \mathrm{pH} 3.6), 10 \mathrm{ml}$ of 2,4,6-tris(2-pyridyl)-5-triazine (TPTZ) solution (10 $\mathrm{mM}$ in $40 \mathrm{mM} \mathrm{HCL})$ and $10 \mathrm{ml}$ of $\mathrm{FeCl}_{3} \cdot 6 \mathrm{H}_{2} \mathrm{O}(20 \mathrm{mM})$ solution. 
Hereafter, a $60 \mu \mathrm{l}$ aliquot of the extract will be mixed with $4.5 \mathrm{ml}$ of FRAP reagent. Then, the outcome of the mixture was incubated in the water bath at $37^{\circ} \mathrm{C}$ for 4 minutes. The absorbance of the mixture was measured at $593 \mathrm{~nm}$ (UVvisible spectrophotometer, Shimadzu UV-160A PC, Shimadzu Corporation, Kyoto, Japan) against a reference platform produced by replacing the extract with water. The FRAP activity was expressed as millimoles of Fe (II) per $100 \mathrm{mg}$ of sample, based on the calibration curve prepared with $\mathrm{FeSO}_{4} \cdot 7 \mathrm{H}_{2} \mathrm{O}$.

\section{F. Determination of DPPH radical activity assay}

The capacity of the extract to scavenge the 2,2-diphenyl1-picrylhydrazyl (DPPH) radical activity assay was performed according to [19]. DPPH reagent was prepared by dissolving $5.9 \mathrm{mg}$ of DPPH powder in $100 \mathrm{ml}$ of methanol, where the mixture was shaken vigorously to ensure that the methanol blended with DPPH powder successfully. After the aforementioned steps, about $0.3 \mathrm{ml}$ of extract solution will be added with $2 \mathrm{ml}$ of DPPH reagent, and subsequently stirred well and kept in a dark environment for 30 minutes. The absorbance of the mixture was measured at $515 \mathrm{~nm}$ by using a UV-visible spectrophotometer (Shimadzu UV-160A PC, Shimadzu Corporation, Kyoto, Japan). The DPPH reagent without the additional extract solution and ethanol were used as the blank reference. The scavenging activity was calculated using below equation [19].

Scavenging activity $(\%)=1-\frac{\text { absorbance samples }}{\text { absorbance control }} \times 100$

\section{G. HPLC analysis of phenolics}

Tea catechin including $\mathrm{C},(+)$-catechin, EC, (-)epicatechin, EGC, (-)-epigallocatechin and GCG, (+)gallocatechin gallate, the gallic acid and caffeic were determined according to the HPLC method described in [20] with slight modification. The HPLC analysis conditions were as follow: injection volume, $10 \mu \mathrm{ml}$; column, SB-C $\mathrm{C}_{18}$ $5 \mu \mathrm{m}, 4.6 \mathrm{~mm} \times 150 \mathrm{~mm}$ (Agilent Technology, USA); oven temperature, $29^{\circ} \mathrm{C}$; mobile phase $\mathrm{A}$, acetonitrile/acetic acid/water (6/1/193); mobile phase $\mathrm{B}$, acetronitrile/acetic acid/water (60/1/139); gradient elution, mobile phase B increased from $30 \%$ to $85 \%$ by linear gradient within $35 \mathrm{~min}$ and further holding at $85 \%$ for $5 \mathrm{~min}$; flow rate, $1 \mathrm{ml} / \mathrm{min}$; detecting wavelength, $280 \mathrm{~nm}$. The concentration factors of the investigated phenolics were determined based on the chromatographic data of the standards. The calibration curves (peak area vs concentration) for individual compounds were obtained for a wide concentration range.

\section{H. Statistical Analysis}

All measurements were carried out in triplicate forms. The data were analyzed using the one-way analysis of variance (ANOVA) tool under the Statistical Package Social Science (SPSS) 17.0 software. The ANOVA and Duncan's Multiple Range test were completed to compile the mean values and standard deviation among the samples.

\section{RESULT AND DISCUSSION}

\section{A. Total phenolic content}

Phenolic compounds in plants are known to behave as free radical scavengers, while it is widely believed that the antioxidant activity produced by most of the plantis mainly due to the presence of phenolic compounds [21]. Basically, antioxidant mechanism of polyphenolic compounds is based on their hydrogen donating and metal ion chelating abilities [22].

Table 1 shows the TPC of different types of tea extracts measured using Folin-Ciocalteu's colorimetric method. In the present study, $50 \%$ of ethanol concentration was used as solvent. For comparison, assays using only distilled water as extraction solvent were also performed, which resulted in $50 \%$ ethanol extracts achieving highest levels of TPC compared to water extracts. Overall, the $50 \%$ ethanol content within GT (186.83 $\mathrm{mg}$ GAE/100 g) has demonstrated the highest effective solvent, while GT in water extraction (184.58 mg GAE/100 g) was the least effective solvent for phenol extraction. The use of ethanol as a solvent provided better extraction results compared to only water usage. Fundamentally, compared to water, phenolic compounds are often more soluble in organic solvents with less polar. The aforementioned results suggest that the extractability of polyphenols is influenced by the polarity and viscosity of the solvents used [23].

Compared to conventional tea, spent tea exhibit lower total phenolic content. OT with $50 \%$ ethanol extract (183.13 $\mathrm{mg}$ GAE/100 g) was found to possess higher value of phenolic than SOT with $50 \%$ ethanol extract $(175.42 \mathrm{mg}$ $\mathrm{GAE} / 100 \mathrm{~g}$ ). In the case of water extraction, conventional tea shows higher phenolic content compared to spent tea. OT in water extract $(180.08 \mathrm{mg}$ GAE/100 g) demonstrated a higher value of TPC compared to SOT in water extract (170.29 mg GAE/100 g). This is expected as spent tea is prepared by brewing the tea leaves in hot boiled water for 5 minutes prior to drying in the oven for 2 days. During the process, some catechins were extracted and resulted in lower total phenolic contents for spent teas compared to conventional teas. These values are higher than those found for some other agroindustrial wastes [ref?]. About $14 \mathrm{mg}$ GAE/g dry matter is reported for both grape pomace [24] and carrot peel waste [25]. Similarly, a total phenolic content of 8.2 and $11.4 \mathrm{mg}$ GAE/100 g dry matters were measured for kiwi and apple peel waste, respectively [26].

The highest TPC value was achieved by GT in $50 \%$ ethanol extract (186.83 mg GAE/g), followed by OT in 50\% ethanol extract (183.13 mg GAE/g) and then BT in 50\% ethanol extract (180.09 $\mathrm{mg} \mathrm{GAE} / \mathrm{g})$. These results are in good agreement with the previous study on tropical and herbal tea [16], which shown the ranking of TPC intensities as green $>$ oolong > black tea. Besides, [27] found that green tea has higher total phenols content $(95.5 \mathrm{mg} \mathrm{GAE} / \mathrm{g}$ ) than black tea (80.1 mg GAE/g). The total phenolic content in different types of tea depend on several factors, namely processing steps during tea manufacturing, leaves processing measures before and after drying, and fermentation and heating of tea leaves. Besides, the catechin contents also depend on the geographical location and growing conditions that include soil, climate agriculture and fertilizer used. 
Green tea is also known as unfermented tea where it does not undergo fermentation or oxidation process due to polyphenol oxidase (PPO), which is an enzyme that exist in tea leaves, and can be deactivated by steaming. Therefore, most of the catechins are preserved and green tea is believed to have the greatest number of total phenolic and flavanoid contents. Furthermore, previous study unveiled that the chemical composition of green tea differs very little from that of the fresh leaves because of being unfermented[28].

In contrast, black tea or fermented tea contains a mixture of catechins, theaflavins, and thearubigens, and produced when the tea leaves undergo a complete fermentation process. As a result, PPO enhance the conversion of the catechins into theaflavins, which is a soluble oxidation products. On the other hand, theaflavin-3,3'-gallate and thearubigens are less soluble and contributes to the color and taste of black tea. Fermentation of black tea is accelerated when the PPO enzyme is released during rolling step [28]. Our results showed that oolong tea holds the total phenolic content at intermediate level. Oolong tea appears to be a hybrid of green and black tea, which is partially fermented compared to black tea.

TABLE I

TOTAL PHENOLIC CONTENT WITH DIFFERENT SOLVENT EXTRACTION (MG GAE/G FRESH WEIGHT)

\begin{tabular}{|l|l|l|}
\hline Type of sample & Water & Ethanol \\
\hline Normal tea & & \\
\hline Black tea & $178.67 \pm 0.63^{\mathrm{dGE}}$ & $180.09 \pm 0.83^{\mathrm{cEF}}$ \\
\hline Oolong tea & $180.08 \pm 0.63^{\mathrm{dEF}}$ & $183.13 \pm 0.21^{\mathrm{deFG}}$ \\
\hline Green tea & $184.58 \pm 2.82^{\mathrm{eG}}$ & $186.83 \pm 1.53^{\mathrm{eG}}$ \\
\hline Spent tea & & \\
\hline Black tea & $165.54 \pm 2.43^{\mathrm{aA}}$ & $172.42 \pm 0.71^{\mathrm{aBC}}$ \\
\hline Oolong tea & $170.29 \pm 2.25^{\mathrm{bB}}$ & $175.42 \pm 0.71^{\mathrm{bD}}$ \\
\hline Green tea & $174.92 \pm 2.25^{\mathrm{cC}}$ & $180.42 \pm 2.34^{\mathrm{cdEF}}$ \\
\hline
\end{tabular}

Results display means values \pm standard deviation $(n=3)$. ${ }^{\text {abc }}$ Mean with different superscripts in column indicate significantly different $(\mathrm{p}<0.05)$ among treatments. ${ }^{\mathrm{ABC}}$ Mean with different superscripts in rows indicate significant difference $(\mathrm{p}<0.05)$ among samples.

\section{B. Total Flavonoid content}

Flavonoids are the most common, important, and widely distributed single group of phenols that are present in plants with highly effective antioxidants [29]. Flavonoids can inhibit metal-initiated lipid oxidation by forming complexes with metal ions [22]. The potential antioxidant activity of flavonoids is associated with the chemical structures with odiphenolic group, a 2-3 double bond conjugated with the 4oxo function and hydroxyl group in the positions 3 and 5 [30]. The total flavonoid content (TFC) of tea was determined as a form of catechin equivalents (CE). The GT also had the highest TFC, followed by OT and BT (Table 2). TFC of $50 \%$ of ethanol extract of BT, OT and GT were 187.33, 295.00 and $347.67 \mathrm{mg} C E Q / 100 \mathrm{~g}$ of dry weight of extract, respectively. The TFC of SBT, SOT and SGT were 136.67, 175.00 and $203.67 \mathrm{mg} \mathrm{CEQ} / 100 \mathrm{~g}$ of dry weight of extract, respectively. TFC of GT is the highest among the three types of tea, and then followed by OT and BT. Furthermore, for water extraction method, TFC for BT, OT and GT were 154.33, 202.00 and $252.67 \mathrm{mg} \mathrm{CEQ} / 100 \mathrm{~g}$ of dry weight of extract, respectively. While TFC of the spent tea in water extraction of SBT, SOT and SGT were 101.67, 132.33 and $140.33 \mathrm{mg}$ CEQ/100 g of dry weight of extract, respectively.

GT in 50\% ethanol (347.67 mg CEQ/100 g) showed highest amount of TFC, compared to water extraction (252.67 mg CEQ/100 g) based. Besides, OT and BT extracted in $50 \%$ ethanol also provided improved result compared OT and BT extracted in water. It is evident that the recovery of flavonoids was solvent and polarity dependent. Furthermore, the solvent polarity will play a key role in increasing phenolic solubility [15]. Spent tea also gives lower TFC compared to normal tea. SBT in 50\% ethanol extract (136.67 mg CEQ/100 g) was found lower compared to BT in $50 \%$ ethanol extracts $(187.33 \mathrm{mg}$ $\mathrm{CEQ} / 100 \mathrm{~g})$. In the case of water extraction, spent tea demonstrates lower phenolic content compared to normal tea. SBT in water extraction (101.67 mg CEQ/100 g) was found to have lower value of TFC compared to $\mathrm{BT}$ in water extraction (154.33 mg CEQ/100 g).

TABLE II

TOTAL FLAVONOID CONTENT WITH DIFFERENT SOLVENT EXTRACTION (MG CEQ/ G FRESH WEIGHT)

\begin{tabular}{|l|l|l|}
\hline Type of sample & Water & Ethanol \\
\hline Normal tea & & \\
\hline Black tea & $154.33 \pm 4.62^{\mathrm{cC}}$ & $187.33 \pm 5.03^{\mathrm{bcD}}$ \\
\hline Oolong tea & $202.00 \pm 4.58^{\mathrm{dE}}$ & $295.00 \pm 8.36^{\mathrm{dG}}$ \\
\hline Green tea & $252.67 \pm 3.79^{\mathrm{eF}}$ & $347.67 \pm 1.72^{\mathrm{eH}}$ \\
\hline Spent tea & & \\
\hline Black tea & $101.67 \pm 4.04^{\mathrm{aA}}$ & $136.67 \pm 3.06^{\mathrm{aB}}$ \\
\hline Oolong tea & $132.33 \pm 4.04^{\mathrm{bB}}$ & $175.00 \pm 7.81^{\mathrm{bD}}$ \\
\hline Green tea & $140.33 \pm 7.57^{\mathrm{bB}}$ & $203.67 \pm 3.79^{\mathrm{cE}}$ \\
\hline
\end{tabular}

Results display means values \pm standard deviation $(n=3)$. ${ }^{\text {abc }}$ Mean with different superscripts in column indicate significantly different $(\mathrm{p}<0.05)$ among treatments. ${ }^{\mathrm{ABC}}$ Mean with different superscripts in rows indicate significant difference $(\mathrm{p}<0.05)$ among samples.

\section{FRAP assay}

FRAP assay is an analysis that is commonly used to study the antioxidant activity of the polyphenols extract of plant materials [15]. Besides, FRAP also measures the antioxidant effect of any substances within the reaction medium. [31]. According to [32], the definition of reducing ability is equivalent to the ability of donating electron from natural antioxidant. This analysis was drawn based on the ability of antioxidant to reduce $\mathrm{Fe}^{3+}$ in 2, 4, 6-tris (1-pyridyl)-5-triazine (TPTZ) solution to $\mathrm{Fe}^{2+}$, forming an intense blue $\mathrm{Fe}^{2}$ - TPTZ complex, which can be measured at $593 \mathrm{~nm}$ by UV-Vis Spectrometer, however the outcome is $\mathrm{pH}$ dependent (optimum $\mathrm{pH}$ 3.6). The absorbance is directly proportional to the antioxidant content [18].

In the current phase of investigation, results of the FRAP assay showed identical trends to that of TPC. Table 3 shows the solvent system that was studied, where GT in50\% ethanol had the highest value $(3614.29 \mu \mathrm{mol} \mathrm{Fe}$ (II)/ $\mathrm{g}$ fresh weight) compared to GT in water (3114.29 $\mu \mathrm{mol} \mathrm{Fe} \mathrm{(II)/} \mathrm{g}$ fresh weight). Earlier, it had been suggested that with the change of solvent polarity, vapour pressure and viscosity, the type of antioxidant compound that being dissolved in solvent also varies. Solvent with low viscosity exhibits low density and high diffusivity that allows them to easily diffuse into 
the pores of the plant materials to leach out the bioactive constituents [14]. As a result, the observed antioxidant activity of the extract varies proportionally [15], [23].

As part of the present analysis, the extracts with aqueous organic solvent of the tea exhibits greater TPC with good power reduction. The reducing potential of antioxidant components is very much associated with their TPC. The plant extracts with higher levels of total phenolics also exhibit greater power reduction [33],[34] .

The GT in 50\% ethanol exhibited high FRAP value of $3814.29 \mu \mathrm{M} \mathrm{FeSO}{ }_{4} .7 \mathrm{H}_{2} \mathrm{O}$ (Table 3), which is significantly different from other tea types $(p>0.05)$, and the outcome demonstrates highest antioxidant capacity among three types of tea studied followed by OT and BT. This trend is also being observed in the reducing activity of spent teas. Meanwhile, the spent tea fractions shown lower FRAP values than normal tea. Many reports have revealed that between antioxidant activity and reducing ability, there is a direct correlation to certain extracts [35]. Besides, bioactive compounds like phenolics are reported to have the total antioxidant power assay in vitro [36]. In this assay, FRAP and total phenolic content showed the same set of trends.

TABLE III

FRAP ASSAY (MMOL FE (II)/G FRESH WEIGHT)

\begin{tabular}{|l|l|l|}
\hline Type of sample & Water & Ethanol \\
\hline Normal tea & & \\
\hline Black tea & $1457.14^{\mathrm{cC}}$ & $2528.57 \pm{ }^{\mathrm{bcD}}$ \\
\hline Oolong tea & $2400.00 \pm{ }^{\mathrm{dE}}$ & $3471.43 \pm^{\mathrm{dG}}$ \\
\hline Green tea & $3114.29 \pm^{\mathrm{F}}$ & $3814.29 \pm{ }^{\mathrm{eH}}$ \\
\hline Spent tea & & \\
\hline Black tea & $314.29 \pm^{\mathrm{aA}}$ & $371.42 \pm^{\mathrm{aB}}$ \\
\hline Oolong tea & $442.86 \pm \pm^{\mathrm{bB}}$ & $642.86 \pm^{\mathrm{bD}}$ \\
\hline Green tea & $728.57 \pm \pm^{\mathrm{bB}}$ & $1028.57 \pm{ }^{\mathrm{CE}}$ \\
\hline
\end{tabular}

Results display means values \pm standard deviation $(\mathrm{n}=3)$. ${ }^{\text {abc }}$ Mean with different superscripts in column indicate significantly different $(p<0.05)$ among treatments. ${ }^{\mathrm{ABC}}$ Mean with different superscripts in rows indicate significant difference $(\mathrm{p}<0.05)$ among samples.

\section{DPPH activity}

DPPH assay is widely used for the determination of free radical scavenging activity of natural antioxidants, mainly due to its simplicity and high sensitivity. In this assay, an antioxidant donates hydrogen or electron, which is then accepted by the DPPH radicals [37]. Upon the changes of DPPH radical to stable diamagnetic molecule, the color property alters from purple to yellow. DPPH radical itself shows a strong absorption characteristics at $515 \mathrm{~nm}$ measured by using spectrophotometer.

Besides FRAP assay, antioxidant capacity of botanical extracts was also studied through free radical-scavenging effect on 1, 1-diphenyl-2-picrylhydrazyl (DPPH) radical [38]. DPPH is a stable organic nitrogen radical and commercially available, where this method is widely used to evaluate the antioxidant activity of different botanical extracts. The antioxidant activity is expressed in the form of percentage of inhibition of DPPH.

Table 4 showed the DPPH scavenging activity to evaluate antioxidant effects. It can be observed that $50 \%$ ethanol extraction exhibited much stronger scavenging ability than water extract. The DPPH value of GT, OT and BT in 50\% ethanol extracts were $89.14,86.97$ and $81.88 \%$ respectively, which demonstrated DPPH higher than GT, OT and BT in water extraction $(87.95,84.86$ and $76.44 \%$ ). In addition, the water extracts exhibited poor scavenging of DPPH and showed the weakest scavenging ability compared to ethanol extracts [34].

Higher DPPH inhibition indicates higher antioxidant activity in tea. GT in $50 \%$ ethanol is observed to have highest antioxidant activity since it shows greatest inhibition of DPPH (89.14\%) followed by OT, BT, SGT, and SOT. However, SBT shows the lowest inhibition (50.14\%).

The trend observed in DPPH results were the same with TPC and TFC. Thus, fundamentally the DPPH scavenging ability may depend on the amount of TPC and TFC in the extracts. The results are in agreement with the literature reported in [22], which stated that extracts enriched with flavanoids or phenolic showed much higher DPPH scavenging ability than those of the other extracts. Findings from this investigation deviated from [16], which reported that the ranking of DPPH scavenging was green > oolong > black, and ranking of power reduction was oolong $>$ green $>$ black.

TABLE IV

ANTIOXIDANT ACTIVITY USING DDPH (RSA) WITH DIFFERENT SOLVENT EXTRACTION ((\%) DPPH INHIBITION)

\begin{tabular}{|l|l|l|}
\hline Type of sample & Water & Ethanol \\
\hline Normal tea & & \\
\hline Black tea & $76.44 \pm 0.52^{\mathrm{dG}}$ & $81.88 \pm 0.27^{\mathrm{dH}}$ \\
\hline Oolong tea & $84.86 \pm 0.15^{\mathrm{el}}$ & $86.97 \pm 0.11^{\mathrm{eJ}}$ \\
\hline Green tea & $87.95 \pm 0.21^{\mathrm{fK}}$ & $89.14 \pm 0.16^{\mathrm{fL}}$ \\
\hline Spent tea & & \\
\hline Black tea & $48.64 \pm 0.21^{\mathrm{aA}}$ & $50.14 \pm 0.58^{\mathrm{aB}}$ \\
\hline Oolong tea & $56.62 \pm 0.67^{\mathrm{bC}}$ & $59.91 \pm 0.48^{\mathrm{bD}}$ \\
\hline Green tea & $64.80 \pm 0.62^{\mathrm{cE}}$ & $70.23 \pm 0.26^{\mathrm{cF}}$ \\
\hline
\end{tabular}

Results display means values \pm standard deviation $(n=3)$. ${ }^{\text {abc }}$ Mean with different superscripts in column indicate significantly different $(\mathrm{p}<0.05)$ among treatments. ${ }^{A B C}$ Mean with different superscripts in rows indicate significant difference $(\mathrm{p}<0.05)$ among samples.

\section{E. HPLC analysis}

Generally, similar phytochemicals are present in different parts of plants, like leaves, fruit and seeds. Catechins are the main polyphenols in tea leaves, and have also been detected in other parts of tea plants, namely flower [39]. The contents of all four catechins, gallic acid and caffeine in the $50 \%$ ethanol extract are shown in Table 5. Gallic acid and caffeine were found in all sample extracts. Gallic acid was ranged from 1.54 to $14.64 \mathrm{mg} / \mathrm{g}$ dry weight of extract and it is highest in GT, followed by OT and BT. Caffeine was ranged from 15.55 to $139.62 \mathrm{mg} / \mathrm{g}$ dry weight of extract. Caffeine was highest in GT, but the least in SBT.

All four catechins were only detected in GT and OT. EC (35.73 mg/g dry weight of extract) and GCG (33.36 mg/g dry weight of extract) of OT were found to be of major catechins. C (11.14 mg/g dry weight of extract) and EGC $(2.99 \mathrm{mg} / \mathrm{g}$ dry weight of extract) were found as minor catechin components in OT. All four catechins in GT were higher valued than OT. However, only GCG $(9.13 \mathrm{mg} / \mathrm{g}$ dry weight of extract) of catechin in BT were detected. 
TABLE V

THE CATECHIN CONTENT IN THE INVESTIGATED EXTRACT FROM TEA (MG/G OF DRY WEIGHT OF EXTRACT)

\begin{tabular}{|l|l|l|l|l|l|l|}
\hline \multirow{2}{*}{ Sample } & Catechin & CF & C & EC & EGC & GCG \\
\cline { 2 - 7 } & GA & $41.89 \pm 0.13^{\mathrm{b}}$ & ND & ND & ND & $9.13 \pm 0.25^{\mathrm{a}}$ \\
\hline BT & $4.48 \pm 0.11^{\mathrm{b}}$ & $101.88 \pm 0.21^{\mathrm{d}}$ & $11.14 \pm 0.19^{\mathrm{a}}$ & $35.73 \pm 0.13^{\mathrm{b}}$ & $2.99 \pm 0.15^{\mathrm{a}}$ & $33.36 \pm 0.11^{\mathrm{c}}$ \\
\hline OT & $9.24 \pm 0.07^{\mathrm{d}}$ & $139.62 \pm 0.16^{\mathrm{e}}$ & $34.69 \pm 0.08^{\mathrm{b}}$ & $88.40 \pm 0.23^{\mathrm{c}}$ & $16.62 \pm 0.12^{\mathrm{b}}$ & $79.46 \pm 0.23^{\mathrm{d}}$ \\
\hline GT & $14.64 \pm 0.08^{\mathrm{e}}$ & $15.55 \pm 0.08^{\mathrm{a}}$ & ND & ND & ND & $3.21 \pm 0.19^{\mathrm{a}}$ \\
\hline SBT & $3.56 \pm 0.03^{\mathrm{a}}$ & $15.52 \pm 0.07^{\mathrm{b}}$ & ND & $13.77 \pm 0.16 \mathrm{a}$ & ND & $16.67 \pm 0.22^{\mathrm{b}}$ \\
\hline SOT & $1.54 \pm 09^{\mathrm{a}}$ & $30.02 \pm 0.12^{\mathrm{b}}$ & $3.67 \pm 0.04^{\mathrm{a}}$ & $47.79 \pm 0.03^{\mathrm{c}}$ \\
\hline SGT & $7.62 \pm 0.05^{\mathrm{c}}$ & $49.34 \pm 0.09^{\mathrm{c}}$ & ND & $47.05 \pm 0.19$ & & \\
\hline
\end{tabular}

50\% ethanol extract; GA, gallic acid; CF, caffeine; C, (+)-catechin; EC, (-)-epicatechin; EGC, (-)-epigallocatechin; and GCG, (-)-gallocatechingallate. ND, not detected. Black tea (BT); Oolong tea (OT); Green tea (GT); Spent black tea (SBT); Spent oolong tea (SOT); Spent green tea (SGT)

(a-e) Means different superscript letter in the same column are significantly different at $\mathrm{p}<0.05$

This might be due to the fermentation process during the tea manufacturing that reduces the levels of catechin significantly. The results from HPLC analysis showed that the value of catechin in spent tea is lower than normal tea. The value of catechin in GT was $34.69 \mathrm{mg} / \mathrm{g}$ dry weight of extract. However, catechin was not detected in SGT. EC (13.77 mg/g dry weight of extract) and GCG (16.67 mg/g dry weight of extract) were majority of catechins that present in OT. Furthermore, $\mathrm{C}$ and EGC was not detected in OT. In SBT, only GCG (3.21 mg/g dry weight of extract) was detected. However, the value of SBT is lower than BT. This result is supported by [40], which stated that large amount of polyphenols and caffeine still remained in tea residues after five continuous extractions. The total amount of catechins was much lower than those of total flavonoids and total phenolics measured by colorimetry. This could be explained by performance of colorimetry which tended to be less accurate than that of HPLC [7].

\section{CONCLUSIONS}

In the present investigation, ethanol demonstrated high efficiency compared to water in extracting phenolics from tea extracts. The polarity of ethanol has influenced the extractability of polyphenols in tea. The Ranking for TPC, TFC, FRAP assay and DPPH scavenging activity was green $>$ oolong $>$ black tea. The phenol contents, flavanoid contents and antioxidant capacities were highest in normal green tea throughout the six fractions of tea studied. In comparison, the normal tea shown higher polyphenol and antioxidant activity than spent tea. There was also a good correlation between TPC and antioxidant capacity of normal and spent tea extracts. The higher the TPC of tea extracts, the higher were the FRAP and DPPH values. In addition to tea catechins, HPLC analysis also implied that some other flavonoids or phenolic compound existed in spent tea. The results indicate that spent tea could be utilized as renewable bio-resource to develop functional food. Furthermore, ethanol extraction could be an effective step for obtaining natural antioxidants from tea although further optimal option of extraction is required.

\section{ACKNOWLEDGMENT}

This work was supported by Universiti Sains Malaysia (USM), Penang, Malaysia.

\section{REFERENCES}

[1] S Khokhar and S G M Magnusdottir, "Total Phenol, Catechin, and Caffeine Contents of Teas Commonly Consumed in the United Kingdom," Journal of Agricultural and Food Chemistry, vol. 50, pp. 565-570, 2002

[2] D Balentine, "Tea and health." Critical Reviews in Food Science and Nutrition, vol. 37, pp. 691-692, 1997

[3] Q K Cheng and Z M Chen, "Tea and health. Beijing, China": Press of Chinese Agricultural Acience. 1994

[4] H Tanizawa, S Toda, T Sazuka, T Taniyama, T Hayashi, and S Arichi, "Natural Antioxidants. I. Antioxidative components of tea leaf (Thea sinensis L.)" Chemical and Pharmaceutical Bulletin, vol. 32, pp. 2011-2014, 1984

[5] A F Alexis, V A Jones, and M J Stiller, "Potential therapeutic applications of tea in dermatology." International Journal of Dermatology, vol. 38, pp. 735-743, 1999

[6] V W Steiwan, Z F Zhang, G P Yu, Q Y Lu, Y L Li, M L Lu, M R Wang, C H Guo, S Z Yu, R C Kurtz, and C C Hsieh, "Protective effect of green tea on the risks of chronic gastritis and stomach cancer." International Journal of Cancer, vol.92, pp. 600-604, 2001

[7] H Wang, K Helliwell, and X You, "Isocratic elution system for the determination of catechins, caffeine and gallic acid in green tea using HPLC." Food Chemistry, vol. 68, pp. 115-121, 2000

[8] X Pan, G Niu, and H Liu, "Microwave-assisted extraction of tea polyphenols and tea caffeine from green tea leaves." Chemical Engineering and Processing, vol. 42, pp. 129-133, 2003

[9] N Salah, N J Miller, G Parganga, L Tifburg, G P Bolwell, and C iceEvan, "Polyphenolic flavonols as scavengers of aqueous phase radicals and as chain-breaking antioxidants." Archives of Biochemistry and Biophysics, vol. 322, pp. 339-346, 1995

[10] K Hosoda, M F Wang, Y C Chang, T Sawaki, and S Yamamoto, "Effect of oolong tea on aging." Japan Food Sci vol. 41, pp. 23-28, 2002

[11] B Frei, and J V Higdon, "Antioxidant activity of tea polyphenols in vivo: evidence from animal studies." Journal of Nutrition, vol. 133, pp. $3275-3284.2003$

[12] A Retvield, and S Wiseman, "Antioxidant effects of tea: evidence from human clinical trials." Journal of Nutrition, vol. 133, pp. 32853292. 2003

[13] M Antolovich, P Prenzler, K Robards, and D Ryan, "Sample preparation in the analysis of phenolic compounds in fruits." Analyst, vol. 125, pp. 989-1009. 2000

[14] M Naczk, and F Shahidi, "Phenolics in cereals, fruits and vegetables: Occurance, extraction and analysis." Journal of Pharmaceutical and Biomedical Analysis, vol. 41, pp. 1523-1542. 2006

[15] M Alothman, R Bhat. and A A Karim, "Antioxidant capacity and phenolic content of selected tropical fruits from Malaysia, extracted with different solvent." Food Chemistry, vol. 115, pp. 785-788. 2009

[16] E W C Chan, Y Y Lim, K L Chong, J B L Tan, and S K Wong, "Antioxidant properties of tropical and temperate herbal teas." Journal of Food Composition and Analysis, vol. 23, pp. 185-189. 2010

[17] X Liu, M Zho, J Wang, B Yang, and Y Jiang, “Antioxidant activity of methanolic extract of emblica fruit (Phyllanthus emblica L.) from 
six regions in China." Journal of Food Composition and Analysis, vol. 21(3), pp. 219-228. 2008

[18] I F F Benzie, and J Strain, "Ferric reducing/ antioxidant power assay: direct measure of total antioxidant activity of biological fluids and modified version for simultaneous measurement of total antioxidant power and ascorbic acid concentration." Method Enzymol, vol. 299, pp. 15-27. 1999

[19] C Sanchez-Moreno, J A Larrauri, and F Saura-Calixto, "A procedure to measure the antiradical efficiency of polyphenols." Journal of the Science of Food and Agriculture, vol. 76, pp. 270-276. 1998

[20] H Liang, Y Liang, J Dong, J Lu, H Xu, and H Wang, "Decaffeination of fresh green tea leaf (Camellia sinensis) by hot water treatment." Food Chemistry, vol. 101, pp. 1451-1456. 2007

[21] M Skerget, P Kotnik, M Hadolin, A R Hras, M Simonic, and Z Knez, "Phenols, proanthocyanidins, flavones and flavonols in some plant materials and their antioxidant activities." Food Chemistry vol. 89, pp. 191-198. 2005

[22] J Lee, N Koo, and D B Min, "Reactive oxygen species, aging, and antioxidative nutraceuticals," Comprehensive Reviews in Food Science and Food Safety, vol. 3, pp. 21-33. 2004

[23] N Turkmen, F Sari, and Y S Velioglu, "Effects of extraction solvents on concentration and antioxidant activity of black and black mate tea polyphenols determined by ferrous tartrate and Folin-Ciocaltue methods." Food Chemistry, vol. 99(4), pp. 835-841. 2006

[24] V Louli, N Ragoussis, and K Magoulas, "Recovery of phenolic antioxidants from wine industry by-products." Bioresour. Technol. Vol. 92, pp. 201-208. 2004

[25] P Chantaro, S Devahastin, and N Chiewchan, "Production of antioxidant high dietary fiber powder from carrot peels." LWT-Food Sci. Technol. Vol 41, pp. 1987-1994. 2008

[26] H H Wijngaard, C Rößle, and N Brunton, "A survey of Irish fruit and vegetable waste and by-products as a source of polyphenolic antioxidants." Food Chem. Vol 116, pp. 202-207. 2009

[27] L Manzocco, M Anese, and M C Nicoli, "Antioxidant properties of extracts as affected by processing." Lebensm. Wiss. -Technol., 31, 694-698. This work was supported by Universiti Sains Malaysia (USM), Penang, Malaysia

[28] D S Wheeler, and W J Wheeler, The medicinal chemistry of tea. Drug dev. Res. 61 45-65, 2004

[29] N V Yanishkieva-Maslarova, Inhibiting oxidation. In J. Pokorny, N. Yanishlieva, \& M.H. Gordon (Eds.), antioxidants in food: Practical
Applications (pp. 22-70) Woodhead Publishing Limited, Cambridge. 2001

[30] L Bravo, Polyphenols: chemistry, dietary sources metabolism, and nutritional significance. Nutrition reviews, 56(11), 317-333, 1998

[31] Y Wang, S Huang, S Shoa, L Qian, and P Xu, Studies of bioactivities of tea (Camellia sinensis L. ) fruit peel extract: Antioxidant activity and inhibitory potential against $\alpha$-glucosidase and $\alpha$-amylas in vitro. Food Chem.,37, 520-526. 2012

[32] J Shi, J Gong, J Liu, X Wu, and Y Zhang, Antioxidant capacity of extract from edible flowers of Prunus mume in China and its active components. LWT- Food Sci. Technol., 42, 477-482. 2009

[33] Z Cheng, L Su, J Moore, K Zhou, M Luther, J J Yin, and L L Yu, Effect of postharvest treatment and heat stress on availability of wheat antioxidants. J. Agric. Food Chem. 2006, 54, 5623-5629.

[34] P Siddhuraju, and $\mathrm{K}$ Becker, Antioxidant properties of various extracts of total phenolic constituents from three different agroclimatic origins of drumstick tree (Moringa oleifera lam.) leaves. J.Agric. Food Chem. 2003, 51, 2144-2155.

[35] P D Duh, P C Du, and G C Yen, Action of methanolic extract of mung bean hulls as inhibitors of lipid peroxidation and non-lipid oxidative damage. Food Chem. Toxicol, 37, 1055-1061.1999

[36] M Serafini, R Bugianesi, G Maiani, S Valtuena, S De Santis., S. and A Crozier. Plasma antioxidants from chocolate. Nature, 424, 1013.2003

[37] J K Moon, and T Shibamoto, Antioxidant assays for plant and food components. Journal of Agricultural and Food Chemistry, 57(5), 1655-1666 2009

[38] B De Ancos, S Sgroppo, L Plaza, and M P Cano, Possible nutritional and health-related value promotion in orange juice preserved by high-pressure treatment. Journal of the Science of Food and Agriculture, 82, 790-796. 2002

[39] Z Yang, Y Tu, S Balderman, F Dong, Y Xu, N Watanabe, Isolation and identification of compounds from ethanolic extract of flowers of the tea (Camellia sinensis) plant and their contribution to the antioxidant capacity. LWT- Food Sci. Technology 42, 1439-1443 2009

[40] Y Zuo, H Chen, and Y Deng, Simultaneous determination of catechins, caffeine and gallic acids in green, oolong, black and pu-erh teas using HPLC with a photodiode array detector. Talanta, 57, 307316. doi:10.1016/S0039-9140(02)00030-9 2002 